\title{
Numerical analysis on daylight transmission and thermal comfort in the environments containing devices called "Double Light Pipes"
}

\author{
O. Boccia*, F. Chella, P. Zazzini \\ D.S.S.A.R.R., Faculty if Architecture University “G. D’Annunzio”, Pescara , Italy \\ *Corresponding author. Tel: +39 854537291, Fax: +39 854537268, E-mail:oreste.boccia@libero.it
}

\begin{abstract}
In this paper the authors present the results of a numerical analysis concerning the study of daylight transmission and thermal comfort in underground areas and basements of a building without any direct openings toward the external environment. The study was carried out on a two-level building, illuminated by the "Double Light Pipe" (DLP), an innovative technological device developed in the Laboratory of Technical Physics, Faculty of Architecture, Pescara, Italy.
\end{abstract}

The DLP consists of two concentric pipes of different diameter, able to illuminate both the final room and the intermediate one and to allow the entry and the extraction of the air inside the environments of life.

In this first phase, the authors carried out a numerical analysis by the soft-wares RADIANCE and ECOTECT with the aim to define the illuminance distribution in the intermediate room illuminated by the DLP in standard conditions of sky; in addition the CFD code FLUENT/AIRPACK is employed with the aim to define the thermal comfort level considering external wind condition, air temperature and solar radiation. The indoor air temperature and velocity, mean age of air and the indexes PMV and PPD have been evaluated so verifying the indoor air quality.

Keywords: Light pipe, Lighting, Daylight, Indoor air quality, Numerical analysis

\section{Introduction}

Buildings use almost $40 \%$ of the world's energy [1] and artificial light is responsible of a significant part of the whole energy consumption of a building. A considerable reduction of energy consumption is achieved when natural light inlet is optimized and this can be achieved both by traditional sources, as windows or skylights, or by technological devices, as light pipes [2, 3]. The latter are particularly suitable in underground areas of buildings, in large commercial or industrial buildings, with windows placed on perimetral walls away from the centre of the room, or in exhibition rooms, museums or similar, where a particularly diffuse light with not too high illuminances on the work plane and a uniform luminance distribution of walls are preferred in order to guarantee a correct perception of the work of arts, particularly paintings on display. Moreover underground areas or rooms without any direct interface outwards need mechanical ventilation systems to make the necessary change of air in order to realize comfortable conditions for the occupants. In this paper the authors address the problem and propose a solution which is the Double Light Pipe (DLP), an innovative technological device recently developed in the laboratory of Technical Physics of Pescara [4, 5]. The DLP is an evolution of a traditional light pipe. The latter transport daylight from the collection point, commonly on the roof top of the building, trough the ceiling to the final rooms where it is distributed by a diffuser $[6,7]$. When an intermediate area has to be crossed by the system, its encumbrance makes it a problem to position the device in the centre of the passage room. The idea is to give the system an illuminating function both for the destination room and the passage area. In this case it becomes acceptable indeed desirable, particularly in wide plant area rooms such as museums or exhibition areas, in which a high quality light, characterized by low illuminances on the work plane and quite a uniform distribution of luminances of the walls, is requested. In this paper the authors present the double light pipe modified in its geometric configuration in order to allow an efficacy circulation of air in the 
passage room able to effect the necessary change of air requested for the comfort of the occupants. This is a ventilated double light pipe, whose performances have been analyzed in the Laboratory of Technical Physics of Pescara through a numerical analysis, by which the thermal and visual comfort level are realized in a large area room without any direct interface to outwards, by the ventilated double light pipe.

\section{Methodology}

A numerical analysis was carried out by the authors: the soft-wares RADIANCE and ECOTECT were used with the aim to calculate the illuminance distribution in the intermediate and final room illuminated by the DLP in various standard conditions of sky. The CFD code FLUENT/ AIRPAK [8] is employed to determine the values of the parameters by which the thermal comfort level for the occupants can be defined, depending on external wind condition, air temperature and solar radiation. In particular, by means of the numerical tool, the indoor air temperature, air velocity, mean age of air and the indexes PMV and PPD have been evaluated in order to verify the indoor air quality. [9]

\subsection{Description of the test room}

The test room modeled by the sw is a two levels square modular form. Each level consists of a 12x12 m plant area room, $4 \mathrm{~m}$ high, in which four ventilated double light pipes are installed, able to introduce daylight both in the passage and the final level, while natural ventilation is achieved in the passage room thanks to openings properly applied on the top and the bottom of the pipes. In Fig. 1 a three-dimensional representation and a cross section of the device are shown. The DLP described in $[4,5]$ is modified in order to allow the air circulation in the room. The inner pipe is narrow at the top and the outside is narrow at the bottom, so the air cavity between the two concentric pipes has a convergent section at the bottom for the introduction of air and the inner pipe has a convergent section at the top for the extraction of air. In the test-room four DLP are installed, two for the extraction and two for the introduction of air. At the top and the bottom of each DLP openings are properly realized in order to allow air introduction and extraction from the environment.
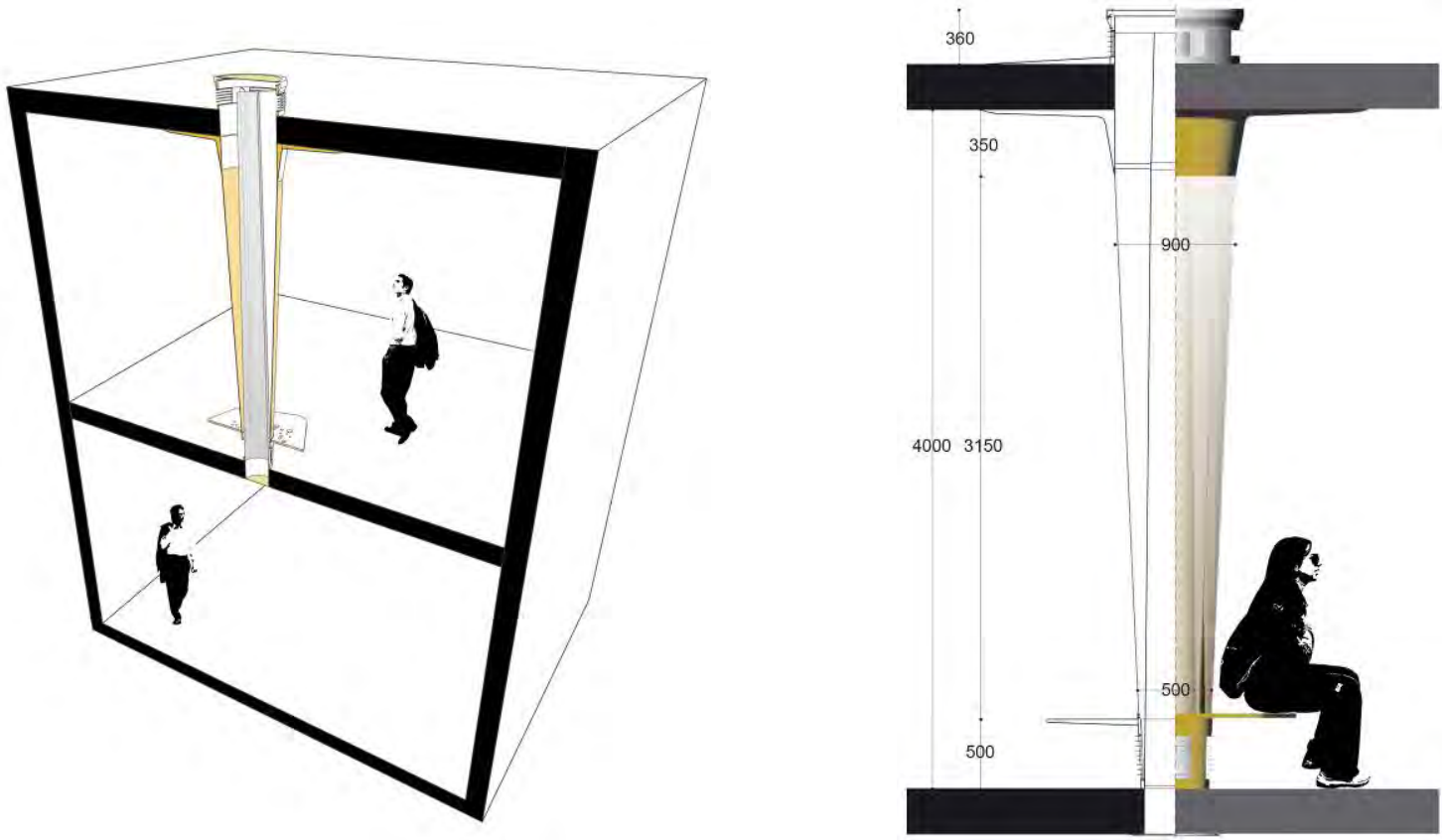

Fig. 1. A three-dimensional representation and a quoted section of the Double Light Pipe 


\section{Daylight results}

In Fig. 2 the daylighting levels distribution on a $0,8 \mathrm{~m}$ high horizontal work plane by the sw Ecotect is illustrated on December the $21^{\text {st }}$ under CIE Overcast sky (a) and on June the $21^{\text {st }}$ under CIE Clear sky (b) .
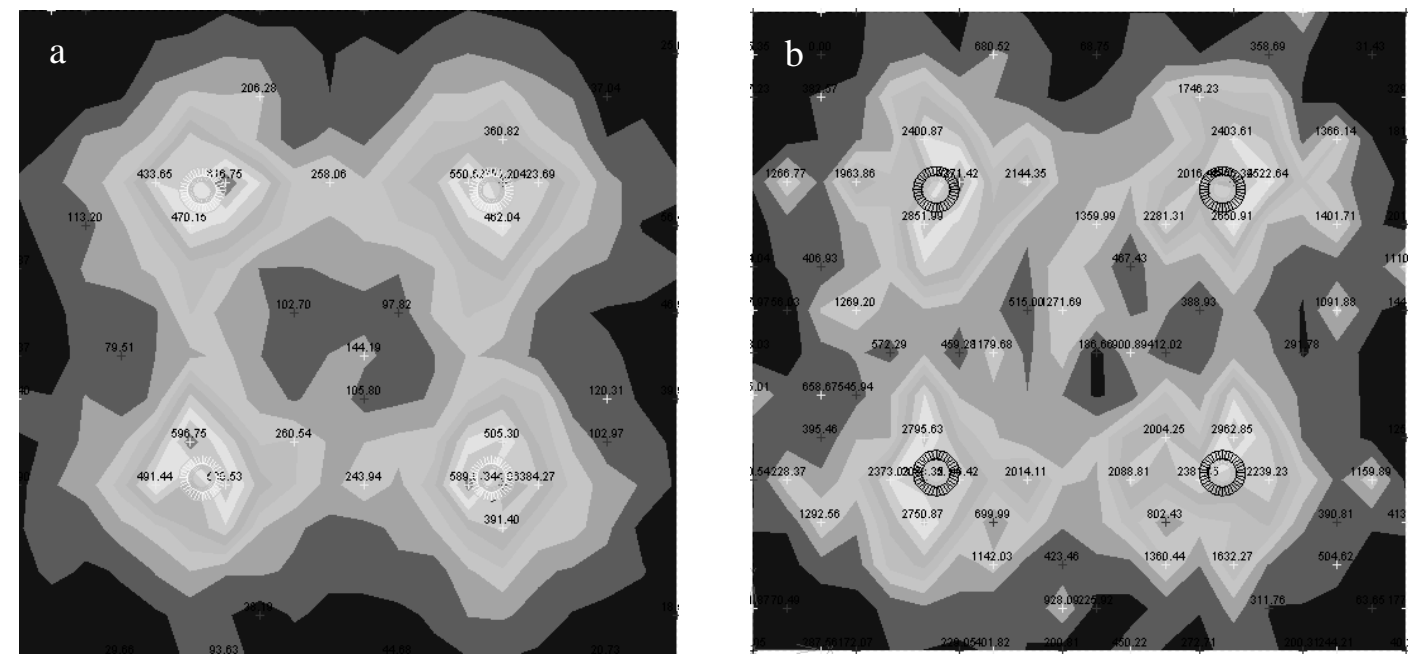

Fig. 2. Daylight Illuminance (lux) by Ecotect in Winter (a) and Summer (b) conditions

In Figg. 3 and 4 the luminance and illuminance data by Radiance are shown, respectively in winter and summer conditions. In the first case, the simulation is effected under Overcast sky on December the $21^{\text {st }}$, while, in the second, under Clear sky on June the $21^{\text {st }}$.
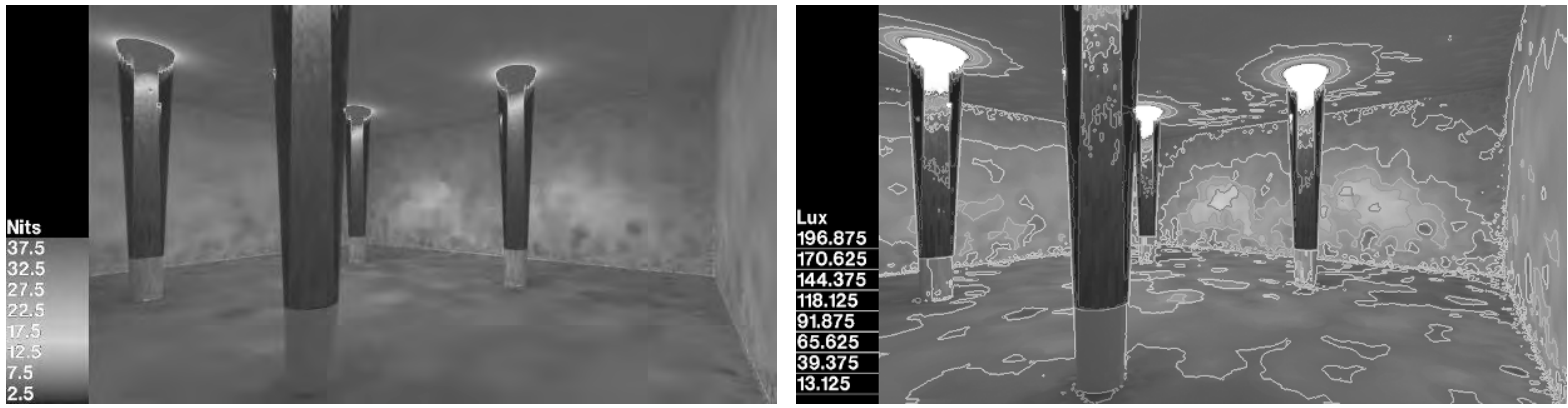

Fig. 3. Daylighting simulation by Radiance in Winter condition
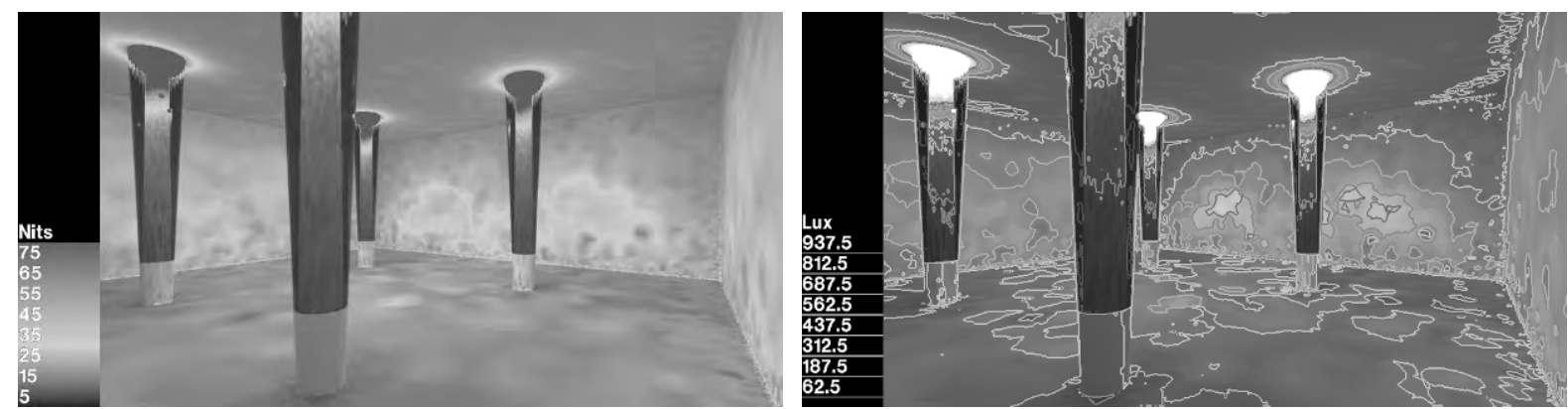

Fig. 4. Daylighting simulation by Radiance in Summer condition

\section{Thermal comfort results}

The numerical analysis was carried out by Fluent/Airpak in steady state summer and winter conditions. The following results regard the test on September the $16^{\text {th }}$ at 13 a.m. with the following boundary conditions: 
External air temperature: $\mathrm{t}_{\mathrm{ext}}=27^{\circ} \mathrm{C}$;

Mean radiant temperature $\mathrm{t}_{\mathrm{mr}}=27^{\circ} \mathrm{C}$;

Mean internal surface temperatures of floor, $\mathrm{t}_{\mathrm{f}}=25^{\circ} \mathrm{C}$

Mean internal surface temperatures of walls $\mathrm{t}_{\mathrm{w}}=26^{\circ} \mathrm{C}$

Mean internal surface temperatures of ceiling $\mathrm{t}_{\mathrm{c}}=26,5^{\circ} \mathrm{C}$

Inlet air velocity close to the vent 1 and $2: \mathrm{v}_{\text {in }}=3 \mathrm{~m} / \mathrm{s}$;

Surface temperature on the polycarbonate collector: $\mathrm{t}_{\mathrm{g}}=36^{\circ} \mathrm{C}$.

The external air temperature was experimentally measured at the same time, while a higher temperature of the collector was imposed to take into account the solar radiation heating.

In Fig. 5 a qualitative trend of air introduction and extraction by the device is shown. Each DLP can function as an extraction or introduction system. In the extraction pipe the inner tube is open at the top and the bottom, and the air cavity is closed, while in the introduction pipe the air cavity is open and the inner pipe is closed.
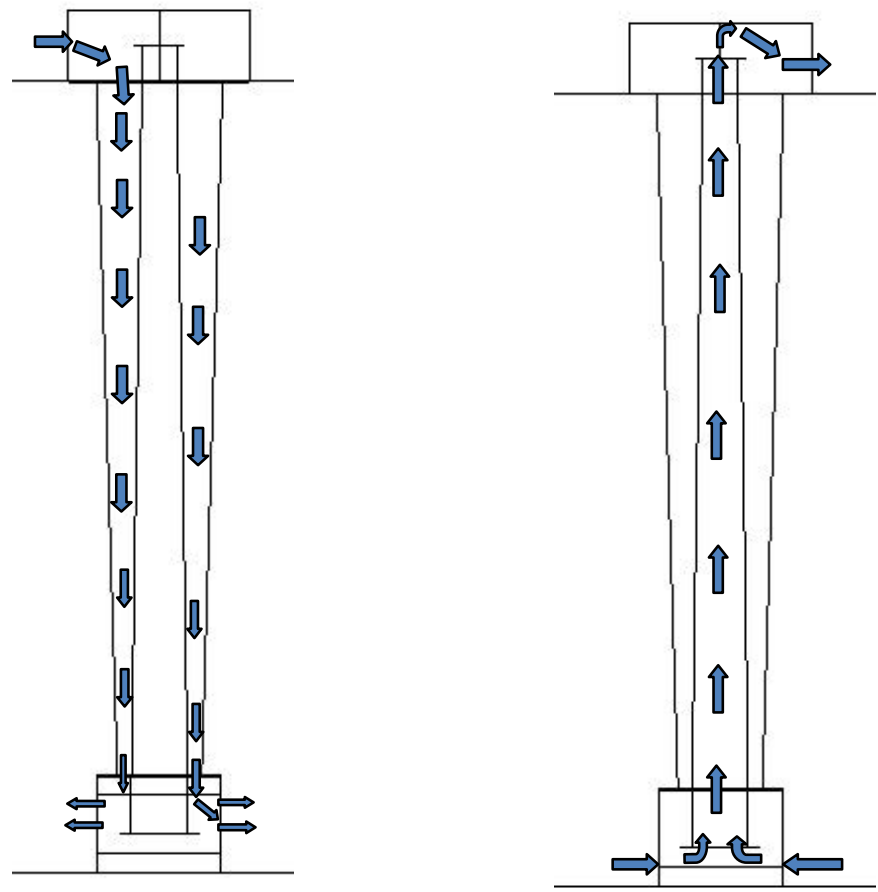

Fig 5. Qualitative Air circulation through the two DLP in the room

In Fig. 6 (a) the air speed distribution on a horizontal plane 1,6 m high on the floor is shown: a good uniformity is verified in the room. In Fig. 6 (b) the air speed distribution is calculated on a vertical cross section $1 \mathrm{~m}$ distant from to the extraction DLP. This last image underlines higher values of speed in correspondence to the openings used for the air circulation. However the air speed is comfortable in the whole environment, with very low values everywhere in the room as confirmed by Fig. 7 (a). The Fig. 7 (b) shows the air temperature on a vertical plane vs the height on the floor. It is evident that a low vertical gradient of temperature is obtained. Fig. 8 confirm this trend. 
(a)

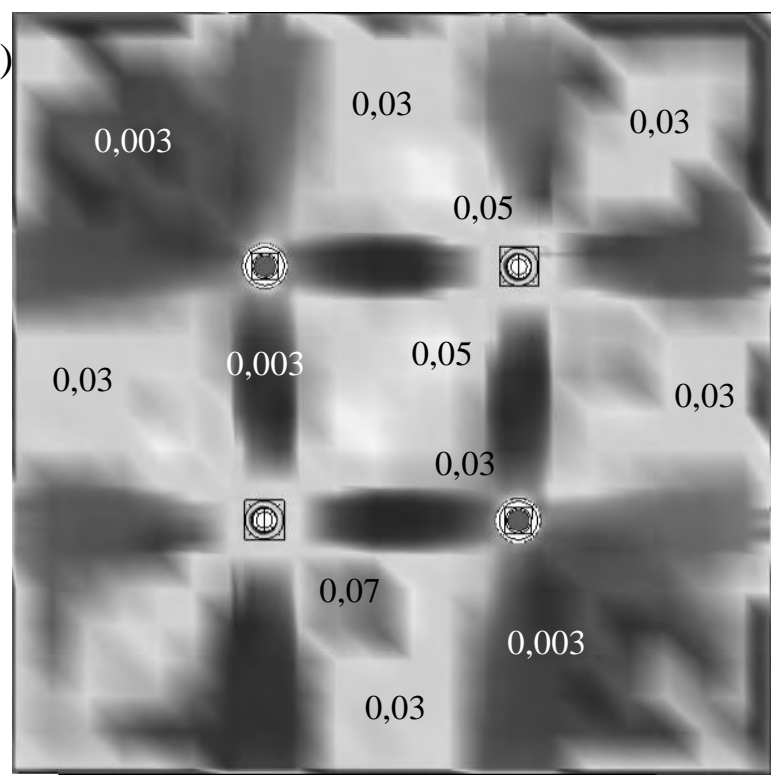

(b)

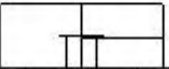

Fig 6. Air speed distribution (m/s) on a horizontal plane 1,6 $\mathrm{m}$ high on the floor (a) and on a vertical plane $1 \mathrm{~m}$ distant from the DLP (b)

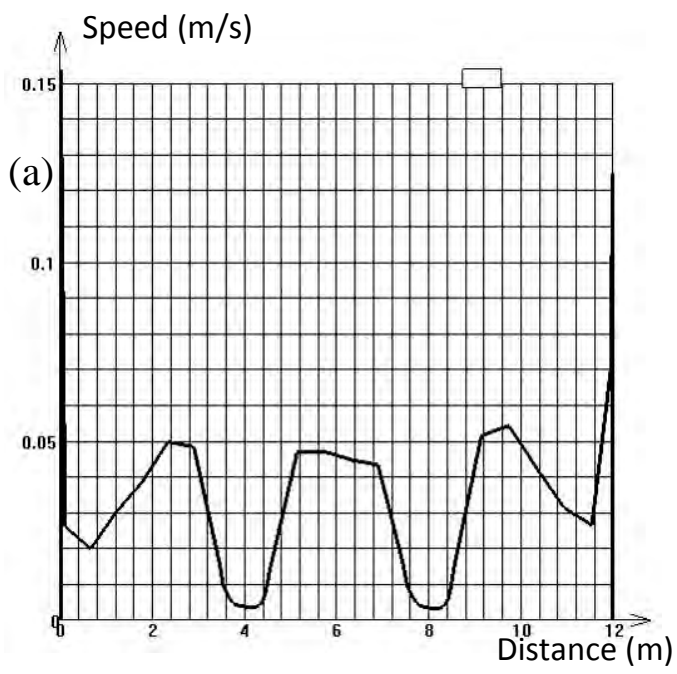

(b)

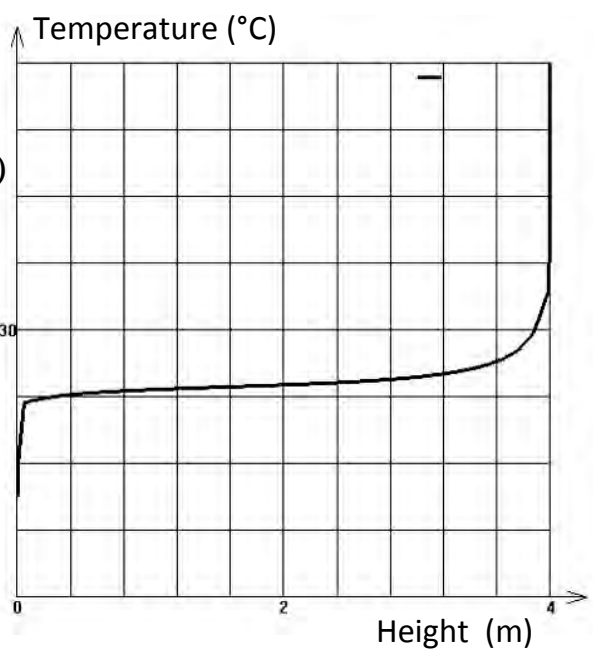

Fig 7. Air speed vs distance from wall to wall at the centre of the room on a horizontal plane 1,6 $\mathrm{m}$ high on the floor (a); air temperature vs height exactly at the centre of the room (b).

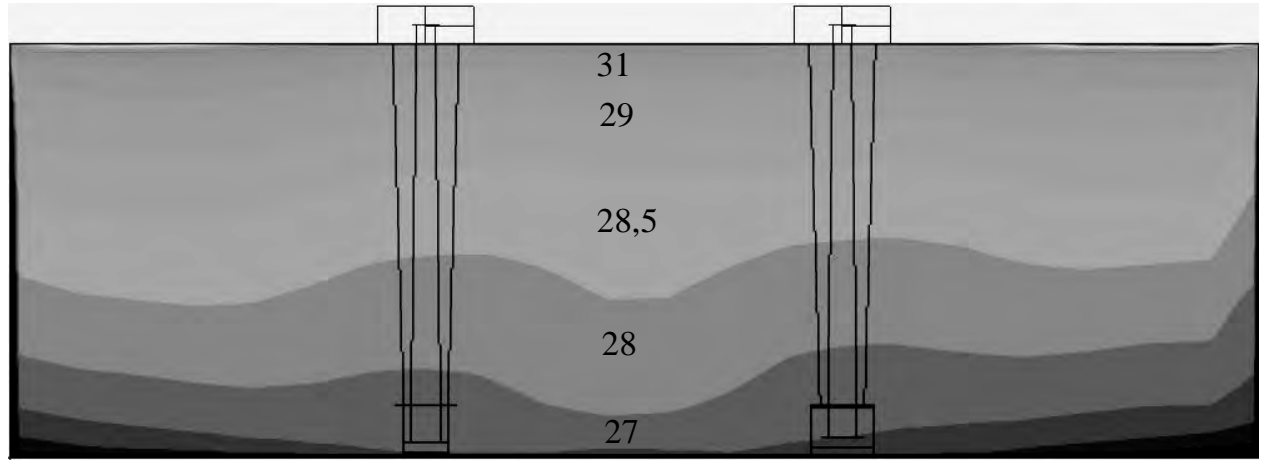

Fig. 8. Air temperature field $\left({ }^{\circ} \mathrm{C}\right)$ on a vertical cross section at the centre of the room 
The predicted mean vote (PMV) is commonly used as a measure of the average response about thermal comfort from a large group of people voting on a range included between -3 and +3 . In this work the PMV has been calculated on a reference horizontal plan in the room and the results are shown in Fig. 9. A satisfactory condition is obtained considering that the PMV is very uniform and close to the optimum value 0 . This is confirmed by the predicted proportion dissatisfied (PPD) index which provides a measure of the percentage of people who will complain of thermal discomfort in relation to the PMV. In this case it is about 13-14 $\%$ as shown in Fig. 10. The PMV and PPD are evaluated considering a metabolic rate level of 1,6 met and a clothing level of 0,9 clo.

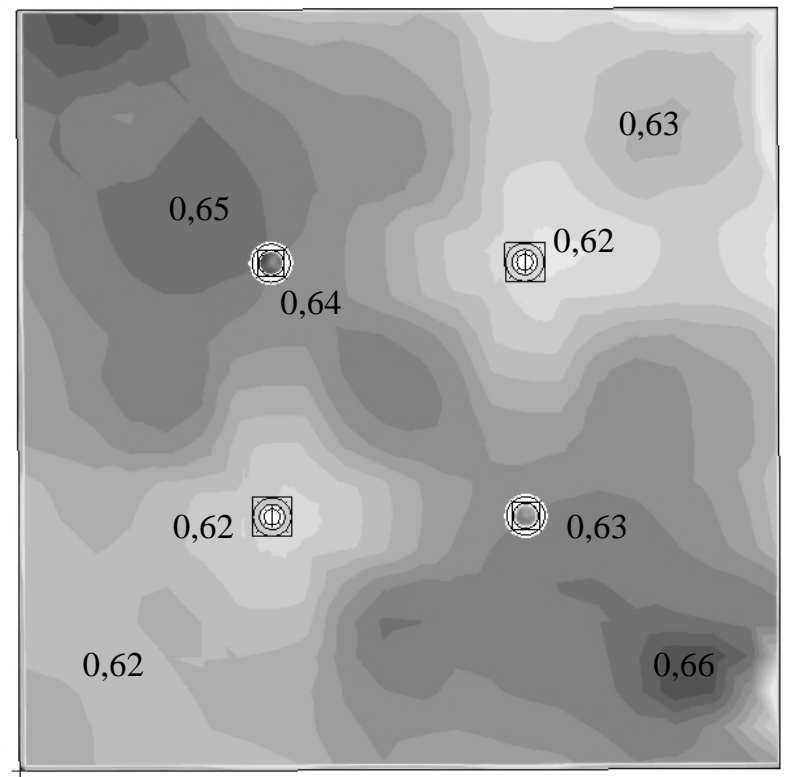

Fig. 9. PMV index distribution on a horizontal plane 1,6 $\mathrm{m}$ high on the floor

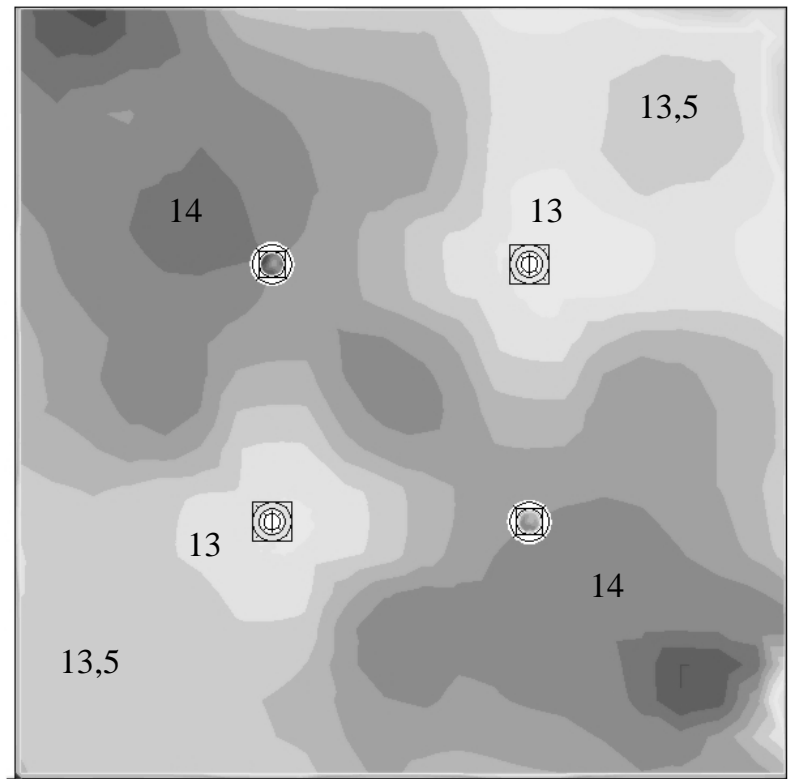

Fig. 10. PPD index distribution (\%) on a horizontal plane 1,6 $\mathrm{m}$ high on the floor

In Fig. 11 the mean age of air distribution calculated by the numerical tool on a horizontal plane 1,6 m high on the floor is shown. It is obviously higher in the corners of the room and very low in correspondence of the DLP where the change of air is very efficacy, but in the whole environment the air change seems to be very comfortable. 


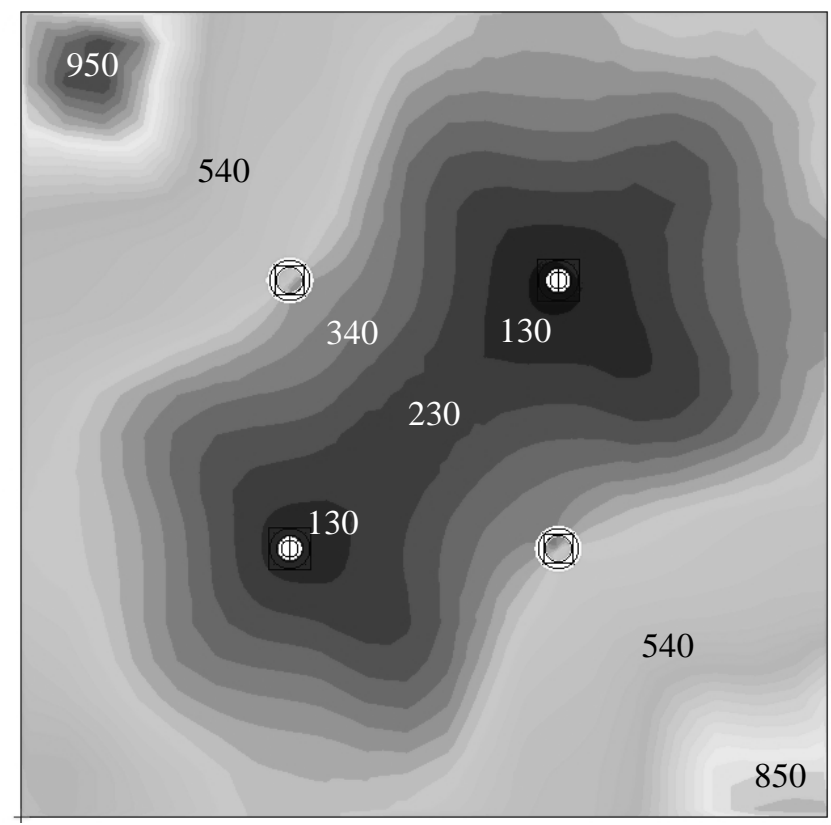

Fig 11. Mean age of air distribution (s) on a horizontal plane 1,6 $\mathrm{m}$ high on the floor

The results obtained in winter conditions are similar to the summer ones about the indoor air speed field, but with higher values. On the contrary the indoor temperatures are obviously very different, as shown in Fig. 12. In winter condition the thermal comfort is not assured due to the absence of a thermal plant.

(a) $\wedge$ Temperature $\left({ }^{\circ} \mathrm{C}\right)$

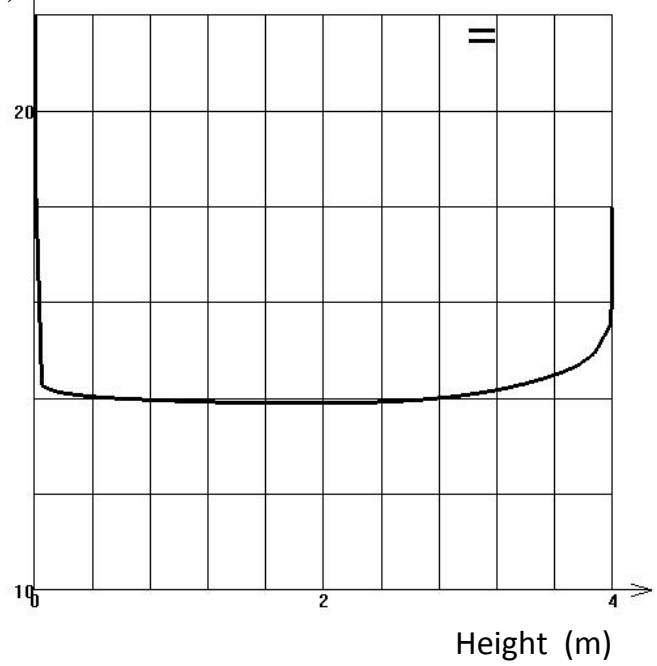

(b)

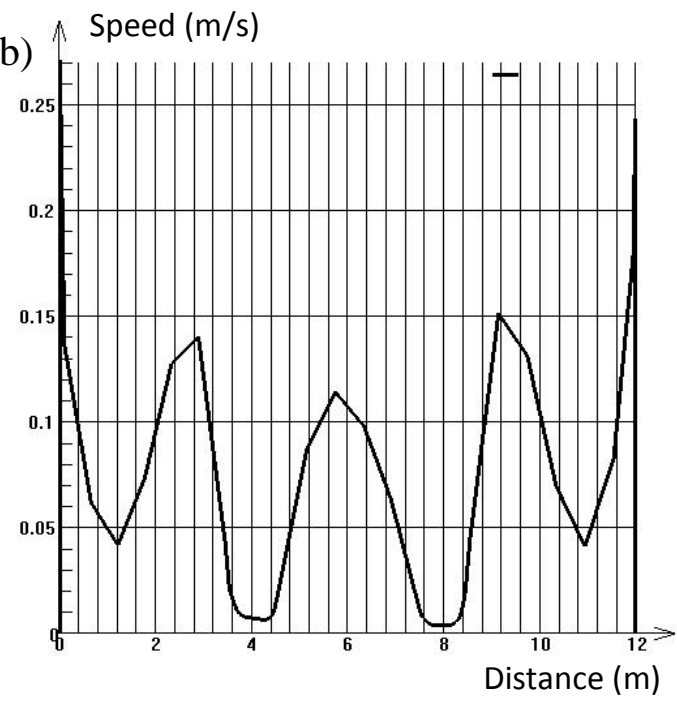

Fig 12. Air temperature vs height exactly at the centre of the room (a); air speed vs distance from wall to wall at the centre of the room on a horizontal plane 1,6 m high on the floor (b) in winter conditions.

\section{Conclusions}

The DLP previously developed by the authors with the aim to distribute daylight in a two/level underground building has been modified in order to allow the air circulation in the upper level necessary to ensure the thermal and hygienic comfort for the occupants. The first numerical results show how the Ventilated Double Light Pipe can be successfully used both to introduce daylight and to allow natural ventilation in the room. It is suitable for large area 
exhibition rooms or museums due to its encumbrance and the features of daylight distribution in the environment. Quite uniform illuminace data with low luminances of the boundary walls of the room is realized, except for the higher portion of the system which is characterized by high luminances with the risk of glare. The authors are developing a solution for this problem, using a diffusing film applied on the upper portion of the system, but this work is chiefly devoted to demonstrate the capacity of the system to be employed as a tool for the air change of the room. The first results encourage the authors to carry on the work. Transient numerical analysis has to be carried out in order to simulate the behavior of the system with various external conditions of wind velocity and test its capacity of making an efficacy change of air of the room.

\section{References}

[1] M. Santamouris, Alternative cooling techniques for building (Keynote lecture), Proceedings of the $6^{\text {th }}$ International Conference on Sustainable Energy Technologies SET 2007, Santiago de Chile, 2007, pp. 19-24.

[2] D. Jenkins, T. Muneer, Modelling light pipe performances-a natural daylight solution, Building and Environment 38, 2003, pp. 965-972.

[3] D. Jenkins, X. Zhang, T. Muneer, Formulation and semi-empirical models for predicting the illuminance of light pipes, Energy Conversion and Management 46, 2005, 2288-2300.

[4] C. Baroncini, F. Chella, P. Zazzini, Numerical and experimental analysis of the Double Light Pipe, a new system for daylight distribution in interior spaces, International Journal of Low Carbon Technologies, 3/2, 2008, pp.110-125.

[5] C. Baroncini, O. Boccia, F. Chella, P. Zazzini, Experimental analysis on a 1:2 scale model of the Double Light Pipe, an innovative technological device for daylight transmission, Solar Energy, 84, 2010, pp.296-307.

[6] Chella, F., Zazzini, P., Carta, G. 2006. Compared numerical and reduced scale experimental analysis on light pipes performances. $5^{\text {th }}$ International Conference on Sustainable Energy Technologies SET 2006, Vicenza, Italy, pp. 263-268.

[7] Zazzini, P., Chella, F., Scarduzio, A. 2006. Numerical and experimental analysis of light pipes' performances: comparison of the obtained results. In Proceedings of PLEA 2006 The 23th Conference on Passive and Low Energy Architecture, Geneva, Switzerland, vol. II, pp. 219-224.

[8] Airpak 2.1 User’s Guid Fluent Inc. April 2002.

[9] ISO 7730:1994. Moderate thermal environments - Determination of the PMV and PPD indices and specification of the conditions for thermal comfort. 